\title{
Sergentomyia (Neophlebotomus) gemmea, a potential vector of Leishmania siamensis in southern Thailand
}

\author{
Kobkan Kanjanopas', Suradej Siripattanapipong ${ }^{2}$, Ubolrat Ninsaeng ${ }^{3}$, Atitaya Hitakarun ${ }^{4}$, Somnat Jitkaew ${ }^{5}$, \\ Preecha Kaewtaphaya ${ }^{6}$, Peerapan Tan-ariya ${ }^{4}$, Mathirut Mungthin ${ }^{2}$, Chetsuda Charoenwong ${ }^{4}$ and \\ Saovanee Leelayoova ${ }^{2^{*}}$
}

\begin{abstract}
Background: Leishmaniasis, caused by Leishmania siamensis, is an emerging disease in Thailand. Although reported cases have been increasing, epidemiological information of the disease including host and vector aspects is not clearly known. This study was a preliminary survey of the potential vector of $L$. siamensis in an affected area of leishmaniasis, Trang Province, southern Thailand.

Methods: The collection of sandflies was performed around the area where a case of leishmaniasis was reported using CDC light traps. Species of sandfly were identified based on morphological characteristics according to Lewis's key. PCR amplification and sequencing of the heat shock protein 70 gene (hsp70) was used to identify L. siamensis DNA in sandflies.

Results: A total of 146 male and female sandflies were collected in the affected areas. Of 71 female sandflies, four species were identified, i.e., Sergentomyia (Neophlebotomus) gemmea, S. (Neophlebotomus) iyengari, S. (Parrotomyia) barraudi and Phlebotomus (Anaphlebotomus) stantoni. Among these species, S. (Neophlebotomus) gemmea was the most predominant species in all areas. DNA of L. siamensis was identified in S. (Neophlebotomus) gemmea. Nucleotide sequences of PCR products using DNA extracted from S. (Neophlebotomus) gemmea showed 99.8\% identity to L. siamensis.

Conclusion: S. (Neophlebotomus) gemmea might be a potential vector of L. siamensis in an affected area, Trang Province, southern Thailand. However further studies are needed to prove whether these sandflies can be natural vectors of leishmaniasis.
\end{abstract}

Keywords: Leishmaniasis, Leishmania siamensis, Sergentomyia (Neophlebotomus) gemmea, Vector, Thailand

\section{Background}

Autochthonous visceral leishmaniasis (VL) caused by Leishmania siamensis, firstly described from southern Thailand in 2008, is now considered an emerging disease in Thailand [1]. Previously, only two autochthonous leishmaniasis cases were reported in Thailand, i.e., in 1999 and 2007; however, the causative species were not identified [2,3]. After 2008, more cases of autochthonous leishmaniasis were reported [4-6]. Characterization of

\footnotetext{
*Correspondence: s_leelayoova@scientist.com

${ }^{2}$ Department of Parasitology, Phramongkutklao College of Medicine, 315

Ratchawithi Road, Ratchathewi, Bangkok 10400, Thailand

Full list of author information is available at the end of the article
}

the causative species, $L$. siamensis was performed and showed that L. siamensis is a novel species $[4,7]$. HIV/ AIDS patients are a high risk group to acquire the infection which can cause not only VL but also disseminated dermal leishmaniasis [4-6]. Until now, the disease has been reported from six provinces in the South, two provinces in the North as well as one province in the East of Thailand [4,6]. Zoonotic transmission of L. siamensis could possibly occur since animal cutaneous leishmaniasis caused by $L$. siamensis was recently reported from Switzerland, Germany and the USA [8-10]. Identification of the vectors is crucial for the prevention and control of the disease. Surveys of sandfly species

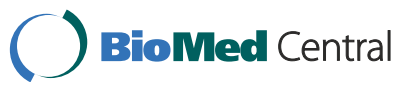


have been conducted in the Central, West, North, Northeast and South of Thailand where Sergentomyia is the most predominant genus reported in all study areas [1,11-14], of which S. (Neophlebotomus) gemmea is the most prevalent in the South [14]. However, the particular species of sandfly that could serve as the vector for leishmaniasis has not yet been demonstrated.

\section{Methods}

In 2011, a sentinel surveillance of sandfly species distribution and their potential vectors was conducted in an affected area, Hat Samran District, Trang Province, southern Thailand where a case of VL-HIV co-infection was reported. The altitude of the affected area is $18 \mathrm{~m}$ above the sea level where palm trees were grown in the area. In August 2011, the average temperature was $27.9^{\circ} \mathrm{C}$ with a humidity of $85.5 \%$. The average wind speed was 1.3 knots and the rainfall was $10.0 \mathrm{~mm}$. Outdoors, a $200-\mathrm{m}$ perimeter surrounding the house included animal enclosures, i.e., cows, goats, pigs, dogs, and Persian cats was surveyed. Neighborhood houses were about $10 \mathrm{~m}$ apart. A palm tree plantation was located about $50 \mathrm{~m}$ away from the house.

To capture sandflies, CDC light traps were placed indoors and outdoors of the patient's house in August, 2011 from 18.00-06.00 h. Outdoors, areas of the 200-m perimeter surrounded house included areas behind the house, spaces under the kitchen, animal enclosures, stacks of bricks and wood in the back yard, banana plants, palm trees, a store house for wood and rice, a thatched roof hut and a nearby abandoned house.

Species of female sandflies were identified by welltrained entomologists based on morphological characteristics $[15,16]$ at the Vector-borne Disease Control Center 11.3, Suratthani Province, Thailand. These female sandflies were pooled in the same microcentrifuge tube containing $70 \%$ alcohol if they shared the same characteristics, i.e., species and collected place. The samples were then sent to the Department of Parasitology, Phramongkutklao College of Medicine for molecular studies. DNA from each pool was extracted using the Genomic DNA Mini Kit (Tissue)
(Geneaid, Taiwan) and evaluated for natural infections with L. siamensis using PCR amplification of the heat shock protein 70 gene ( $h s p 70)$ and the internal transcribed spacer 1 region (ITS1) of the small subunit ribosomal RNA (SSU-rRNA) gene. For the $h s p 70$, PCR was performed using primers HSP70sen and HSP70ant with the conditions previously described [17]. For the ITS1, the method of El Tai et al. (2001) was performed [18]. DNA sequencing was then conducted by 1 st Base Pte. Ltd., Singapore. All PCR products positive for $h s p 70$ gene were ligated with pGEM-T Easy vector (Promega, WI, USA) and cloned into E.coli JM109. Three clones of each positive pool were selected and sequenced.

The 18s rRNA region of each pool sandfly sample was amplified using primers Lu.18S rRNA-1S and Lu.18S rRNA-1R with conditions previously described by Kato et al. [19]. The PCR products from each pool were then directly sequenced.

The minimum infection rate (MIR) was calculated using the standard formula: [number of positive pools / total specimens tested] $x$ 1000), with the data representing a single sandfly species, collected over a time period and geographic area.

\section{Results}

A total of 146 captured sandflies were collected with a female:male ratio of $1: 1.1$. Of 71 female sandflies, four species were identified of which Sergentomyia (Neophle botomus) gemmea (49.3\%) was the most predominant species, followed by S. (Neophlebotomus) iyengari (42.3\%), S. (Parrotomyia) barraudi (4.2\%) and Phlebotomus (Ana phlebotomus) stantoni (4.2\%) (Table 1). The most common habitat of sandflies was at the cow corral (39.4\%) followed by the thatched roof hut (26.8\%). Others were the chicken stall $(19.7 \%)$, the store house (7.1\%), banana plants $(4.2 \%)$ and the abandoned house (2.8\%). S. (Neophle botomus) gemmea was found at all mentioned habitats, mostly at the cow corral and the thatched roof hut. None were trapped indoors.

All sequencing results from the cloning of positive hsp70 amplification showed identical amplicon sizes at

Table 1 Species and habitats of trapped female sandflies in the study area

\begin{tabular}{|c|c|c|c|c|c|c|c|}
\hline \multirow[t]{2}{*}{ Sandfly species } & \multicolumn{7}{|c|}{ Areas of trapped sandflies } \\
\hline & $\begin{array}{l}\text { Cow } \\
\text { corral }\end{array}$ & $\begin{array}{l}\text { Chicken } \\
\text { stall }\end{array}$ & $\begin{array}{l}\text { Banana } \\
\text { plants }\end{array}$ & $\begin{array}{l}\text { Thatched roof } \\
\text { hut }\end{array}$ & Woodshed & $\begin{array}{l}\text { Abandoned } \\
\text { house }\end{array}$ & Total \\
\hline $\begin{array}{l}\text { Phlebotomus (Anaphlebotomus) } \\
\text { stantoni }\end{array}$ & 2 & - & - & - & - & 1 & $3(4.2 \%)$ \\
\hline $\begin{array}{l}\text { Sergentomyia (Neophlebotomus) } \\
\text { gemmea }\end{array}$ & 17 & 1 & 2 & 11 & 3 & 1 & $\begin{array}{c}35 \\
(49.3 \%)\end{array}$ \\
\hline $\begin{array}{l}\text { Sergentomyia (Neophlebotomus) } \\
\text { iyengari }\end{array}$ & 7 & 12 & 1 & 8 & 2 & - & $\begin{array}{c}30 \\
(42.3 \%)\end{array}$ \\
\hline Sergentomyia (Parrotomyia) barraudi & 2 & 1 & - & - & - & - & $3(4.2 \%)$ \\
\hline Total & 28 (39.4\%) & $14(19.7 \%)$ & $3(4.2 \%)$ & 19 (26.8\%) & $5(7.1 \%)$ & $2(2.8 \%)$ & 71 (100\%) \\
\hline
\end{tabular}


1,422 bp using extracted DNA of trapped S. (Neophle botomus) gemmea, which showed $99.8 \%$ identity to the hsp70 of L. siamensis (GenBank accession number JX852709). GenBank accession numbers of the representative nucleotide sequences of $L$. siamensis detected in S. (Neophlebotomus) gemmea were assigned as JX852708. Positive samples were from two pools of S. (Neophle botomus) gemmea females; the first pool was trapped at the cow corral near the house (10 females) and the other was collected at the store house (3 females). Unfortunately, we could not amplify the ITS1 from these samples. Determining the 18s rRNA of sandflies showed the consensus among nucleotide sequences from these L. siamensis- positive S. (Neophlebotomus) gemmea samples. One of these sequences was submitted to GenBank under accession number KF112045. The minimum infection rate (MIR) was 57.1 since there were two L. siamensis-positive pools and a total of 35 collected S. (Neophlebotomus) gemmea.

\section{Discussion}

In the present study, we reported S. (Neophlebotomus) gemmea as a potential vector of leishmaniasis caused by L. siamensis in Thailand. PCR amplification and sequence analysis of the $h s p 70$ gene demonstrated L. siamensis DNA in S. (Neophlebotomus) gemmea captured in the affected area where a case of VL-HIV co-infection was reported. Unfortunately, the infection rate of S. (Neophlebotomus) gemmea could not be determined since we used the DNA of pooled samples. To date, no report has identified the possible role of S. (Neophlebotomus) gemmea as vector of any Leishmania species from any other geographical areas. In fact, Sergentomyia species were rarely considered as vector of medically important Leishmania since they prefer animal blood. Only a few studies could detect Leishmania DNA in Sergentomyia. A study in India identified L. donovani DNA in S. babu [20], while Parvizi \& Amirkhani (2008) identified L. major DNA in $S$. sintoni in Iran [21]. Recently L. major DNA was also detected in S. (Spelaeomyia) darlingi collected from zoonotic cutaneous leishmaniasis affected areas in Mali [22]. Moreover, L. major was also isolated from S. garnhami and successfully cultured in NNN medium [23]. Since Sergentomyia sandflies are zoophilic, they might have a role in the transmission of zoonotic leishmaniasis. Leishmaniasis caused by L. siamensis might be also zoonotic since phylogenetic analysis showed that $L$. siamensis was closely related to $L$. enrietti, a Leishmania species infecting Brazilian guinea pigs [6]. In addition, L. siamensis DNA was identified in animals such as rats and dogs (personal communication).

The distribution of sandfly species in the present study was similar to our previous report showing that S. (Neophlebotomus) gemmea was predominant in southern
Thailand, the affected area of leishmaniasis caused by L. siamensis [14]. Unfortunately, we could not detect L. siamensis by PCR in any samples of the previous survey [14]. Of the 26 species of sandflies described in different regions of Thailand [11], the distribution of species in the South was different from other parts of Thailand $[11,14]$. All captured S. (Neophlebotomus) gemmea were found outdoors where the cow corral was the most common habitat. Habitat preference could be related to their blood meal feeding. In this study, we identified S. (Neophlebotomus) gemmea based on morphological characteristics $[15,16]$. The 18s rRNA of L. siamensispositive $S$. (Neophlebotomus) gemmea was amplified and sequenced. The nucleotide sequence was then submitted to GenBank. Unfortunately no other 18s rRNA nucleotide sequence of $S$. (Neophlebotomus) gemmea is available to be compared in GenBank. Since the chromatogram of nucleotide sequences showed a completed consensus, we postulated that each pool contained only one species.

\section{Conclusion}

Our study showed that $S$. (Neophlebotomus) gemmea might be a vector of $L$. siamensis, the causative agent of leishmaniasis in Thailand. Further studies with larger samples are urgently needed to determine the potential sandfly vectors, their infection rate and behaviors such as host-preference behavior, blood meal feeding and breeding habitat in all affected areas of leishmaniasis. In addition, the natural reservoir host should be identified. The awareness of the disease by public health personnel and community health workers as well as having an effective vector control program are important keys to prevent the disease from spreading.

\section{Competing interests}

The authors declare that they have no competing interests.

\section{Authors' contribution}

KK, PT, MM and SL designed the study protocol. UN, SK and PJ collected and determined species of sandflies. SS, AH and CC performed PCR tests. KK, SS, MM and SL drafted and revised the manuscript. All authors have given approval to the final version of the manuscript.

\section{Acknowledgements}

We would like to thank all staff of the Vector-borne Disease Control Center 11.3, Surat Thani Province and the Vector-borne Disease Control Center 12.3, Trang Province, Ministry of Public Health, Thailand for their cooperation. This study was supported by the Thai Ministry of Public Health and

Phramongkutklao College of Medicine.

\section{Author details}

${ }^{1}$ Ministry of Public Health, Nonthaburi Province 11000, Thailand. ${ }^{2}$ Department of Parasitology, Phramongkutklao College of Medicine, 315 Ratchawithi Road, Ratchathewi, Bangkok 10400, Thailand. ${ }^{3}$ The Vector-borne Disease Control Center 11.3, Ministry of Public Health, Suratthani Province, Thailand. ${ }^{4}$ Faculty of Science, Mahidol University, Bangkok, Thailand. ${ }^{5}$ The Vector-borne Disease Control Center 12.3, Ministry of Public Health, Trang Province, Thailand.

${ }^{6}$ Yantakao Hospital, Trang Province, Thailand.

Received: 15 February 2013 Accepted: 15 July 2013

Published: 19 July 2013 


\section{References}

1. Sukmee T, Siripattanapipong S, Mungthin M, Worapong J, Rangsin R, Samung Y, Kongkaew W, Bumrungsana K, Chanachai K, Apiwathanasorn C, Rujirojindakul P, Wattanasri S, Ungchusak K, Leelayoova S: A suspected new species of Leishmania, the causative agent of visceral leishmaniasis in a Thai patient. Int J Parasitol 2008, 38:617-622.

2. Thisyakorn U, Jongwutiwes $S$, Vanichsetakul P, Lertsapcharoen P: Visceral leishmaniasis: the first indigenous case report in Thailand. Trans $R$ Soc Trop Med Hyg 1999, 93:23-24.

3. Kongkaew W, Siriarayaporn P, Leelayoova S, Supparatpinyo K, Areechokchai D, Duang-ngern P, Chanachai K, Sukmee T, Samung Y, Sridurongkathum P: Autochthonous visceral leishmaniasis: a report of a second case in Thailand. Southeast Asian J Trop Med Public Health 2007, 38:8-12.

4. Suankratay C, Suwanpimolkul G, Wilde H, Siriyasatien P: Autochthonous visceral leishmaniasis in a human immunodeficiency virus (HIV)-infected patient: the first in Thailand and review of the literature. AmJTrop Med Hyg 2010, 82:4-8.

5. Chusri S, Hortiwakul T, Silpapojakul K, Siriyasatien P: Consecutive cutaneous and visceral leishmaniasis manifestations involving a novel Leishmania species in two HIV patients in Thailand. AmJTrop Med Hyg 2012, 87:76-80.

6. Bualert L, Charungkiattikul W, Thongsuksai P, Mungthin M, Siripattanapipong S, Khositnithikul R, Naaglor T, Ravel C, El-Baidouri F, Leelayoova S: Autochthonous disseminated dermal and visceral leishmaniasis in an AIDS patient, southern Thailand, caused by Leishmania siamensis. AmJTrop Med Hyg 2012, 86:821-824.

7. Leelayoova S, Siripattanapipong S, Hitakarun A, Kato H, Tan-ariya P Siriyasatien $P$, Osatakul S, Mungthin M: Multilocus characterization and phylogenetic analysis of Leishmania siamensis isolated from autochthonous visceral leishmaniasis cases, southern Thailand. BMC Microbiol 2013, 13:60.

8. Lobsiger L, Müller N, Schweizer T, Frey CF, Wiederkehr D, Zumkehr B, Gottstein B: An autochthonous case of cutaneous bovine leishmaniasis in Switzerland. Vet Parasitol 2010, 169:408-414.

9. Müller N, Welle M, Lobsiger L, Stoffel MH, Boghenbor KK, Hilbe M, Gottstein B, Frey CF, Geyer C, von-Bomhard W: Occurrence of Leishmania sp. in cutaneous lesions of horses in Central Europe. Vet Parasitol 2009, 166:346-351.

10. Reuss SM, Dunbar MD, Calderwood Mays MB, Owen JL, Mallicote MF, Archer LL, Wellehan JF Jr: Autochthonous Leishmaniasiamensis in Horse, Florida, USA. Emerg Infect Dis 2012, 18:1545-1547.

11. Apiwathnasorn C, Samung Y, Prummongkol S, Phayakaphon A, Panasopolkul C: Cavernicolous species of phlebotomine sand flies from Kanchanaburi Province, with an updated species list for Thailand. Southeast Asian J Trop Med Public Health 2011, 42:1405-1409.

12. Polseela R, Apiwathnasorn C, Samung Y: Seasonal variation of cavedwelling phlebotomine sandflies (Diptera:Psychodidae) in PhraPhothisat Cave, Saraburi Province, Thailand. Southeast Asian J Trop Med Public Health 2007, 38:1011-1015.

13. Polseela R, Apiwathnasorn C, Samung Y: Seasonal distribution of phlebotomine sand flies (Diptera: Psychodidae) in Tham Phra Phothisat temple, Saraburi province, Thailand. Trop Biomed 2011, 28:366-375.

14. Sukra K, Kanjanopas K, Amsakul S, Rittaton V, Mungthin M, Leelayoova S: A survey of sandflies in the affected areas of leishmaniasis, southern Thailand. Parasitol Res 2013, 112:297-302.

15. Lewis DJ: The Phlebotomine sand flies (Diptera: Psychodidae) from the Oriental region. Bull Brit Mus Nat Hist (Ent) 1978, 37:217-343.

16. Lewis DJ: Phlebotomine sandflies (Diptera: Psychodidae) from the Oriental region. Syst Entomol 1987, 12:163-180.

17. Montalvo AM, Fraga J, Monzote L, Montano I, De-Doncker S, Dujardin JC, Van der-Auwera G: Heat-shock protein 70 PCR-RFLP: a universal simple tool for Leishmania species discrimination in the New and Old World. Parasitology 2010, 137:1159-1168

18. El-Tai NO, El-Fari M, Mauricio I, Miles MA, Oskam L, El-Safi SH, Presber WH, Schönian G: Leishmania donovani: intraspecific polymorphisms of Sudanese isolates revealed by PCR-based analyses and DNA sequencing. Exp Parasitol 2001, 97:35-44.

19. Kato H, Uezato H, Katakura K, Calvopiña M, Marco JD, Barroso PA, Gomez EA, Mimori T, Korenaga M, Iwata H, Nonaka S, Hashiguchi Y: Detection and identification of Leishmania species within naturally infected sand flies in the andean areas of Ecuador by a polymerase chain reaction. AmJTrop Med Hyg 2005, 72:87-93.
20. Mukherjee S, Hassan MQ, Ghosh A, Ghosh KN, Bhattacharya A, Adhya S: Short report: Leishmania DNA in Phlebotomus and Sergentomyia species during a kala-azar epidemic. AmJTrop Med Hyg 1997, 57:423-425.

21. Parvizi P, Amirkhani A: Mitochondrial DNA characterization of Sergentomyia sintoni populations and finding mammalian Leishmania infections in this sandfly by using ITS-rDNA gene. Iranian J Vet Res 2008, 22:9-18.

22. Berdjane-Brouk Z, Koné AK, Djimdé AA, Charrel RN, Ravel C, Delaunay $\mathrm{P}$, Del-Giudice P, Diarra AZ, Doumbo S, Goita S, Thera MA, Depaquit J, Marty P, Doumbo OK, Izri A: First detection of Leishmania major DNA in Sergentomyia (Spelaeomyia) darlingi from cutaneous leishmaniasis foci in Mali. PLoS One 2012, 7:e28266.

23. Mutinga MJ, Massamba NN, Basimike M, Kamau CC, Amimo FA, Onyido AE, Omogo DM, Kyai FM, Wachira DW: Cutaneous leishmaniasis in Kenya: Sergentomyia garnhami (Diptera Psychodidae), a possible vector of Leishmania major in Kitui District: a new focus of the disease. East Afr Med J 1994, 71:424-428.

doi:10.1186/1471-2334-13-333

Cite this article as: Kanjanopas et al: Sergentomyia (Neophlebotomus) gemmea, a potential vector of Leishmania siamensis in southern Thailand. BMC Infectious Diseases 2013 13:333.

\section{Submit your next manuscript to BioMed Central and take full advantage of:}

- Convenient online submission

- Thorough peer review

- No space constraints or color figure charges

- Immediate publication on acceptance

- Inclusion in PubMed, CAS, Scopus and Google Scholar

- Research which is freely available for redistribution

Submit your manuscript at www.biomedcentral.com/submit
C Biomed Central 